\title{
STRATEGI MEMBIDIK KETERSEDIAAN AUDIENS DALAM INDUSTRI TELEVISI (Studi Deskriptif Tayangan Film India ANTV)
}

\author{
Rubiyanto \\ Magister IImu Komunikasi, Sekolah Pascasarjana Universitas Sahid Jakarta \\ Disetujui 19 Maret 2018
}

\begin{abstract}
The success of ANTV captured the attention of the audience through the Indian Movie show influenced ANTV's position to television in the first rank. The television, which used to be in the last number among rival televisions, tried the first time to broadcast an Indian movie called Mahabharata, which had been successfully aired by TPI in the 1990s. The latest version of the Indian movie gets a great reception from the audience. This article aims to describe ANTV's strategy in the television industry through Indian movie to win the competition. According to Pringle and Starr (2006: 123-125), when planning a program to be aired, the television managers should pay attention to the nine factors, namely (1) Strength or Weakness of Competing Stations, (2) Building Audience Flow, (3) Building Audience Habit, (4) Available Audience, (5) Audience Interest, (6) Advertiser Interest, (7) Budget, (8) Inventory Program, and (9) Local Production Capabilities. The authors limit this study to the available audience and the scheme programing of ANTV. The research method used qualitative descriptive with data collection technique, consist of interview, observation, and documentation. Based on the results of research and data analysis can be concluded that the Indian movie impressions in accordance with the ANTV audience target, so this show succeeded in drawing the attention of the audience, and became the top program. Scheme of ANTV programs illustrate the suitability of the broadcast time slot division and the available audience. These two conclusions refer to Pringle and Starr's thoughts. ANTV's strategy review to win the competition in the television industry opens up a new idea. In this research describe not only on-air programs but also strengthened by off-air program.
\end{abstract}

Keywords: Program, Indian Movie, ANTV, Available Audience

\begin{abstract}
ABSTRAK
Keberhasilan ANTV merebut perhatian audiens melalui tayangan Film India memengaruhi posisi ANTV menjadi televisi di peringkat pertama. Televisi yang tadinya berada di nomor buncit di antara televisi saingan, mencoba kali pertama menayangkan film India berjudul Mahabharata, yang pernah sukses ditayangkan TPI tahun 1990-an. Versi terbaru film India ini mendapat sambutan luar biasa dari audiens. Artikel ini bertujuan mendeskripsikan strategi ANTV dalam industri televisi melalui tayangan film India untuk memenangkan persaingan. Menurut Pringle dan Starr (2006:123-125), ketika merencanakan sebuah program yang akan ditayangkan hendaknya pengelola televisi memperhatikan Sembilan faktor, yaitu: (1) Strength or Weakness of Competing Stations, (2) Building Audience Flow, (3) Building Audience Habit, (4) Available Audience, (5) Audience Interest, (6) Advertiser Interest, (7) Budget, (8) Program Inventory, dan (9) Local Production Capabilities. Penulis membatasi kajian pada ketersediaan audiens (available audience) dikaitkan dengan daypart pada pola pemrograman ANTV. Metode penelitian menggunakan kualitatif deskriptif dengan teknik pengumpulan data, terdiri dari wawancara, observasi, dan dokumentasi. Berdasarkan hasil penelitian dan analisis data dapat disimpulkan bahwa tayangan film India sesuai dengan target audiens yang diusung ANTV, sehingga tayangan ini
\end{abstract}

\footnotetext{
*Korespondensi Penulis:

E-mail: rb_yanto@yahoo.com
} 
berhasil menyedot perhatian penonton, dan menjadi program unggulan. Penjadwalan program acara di ANTV menggambarkan kesesuaian pembagian slot waktu siaran dan ketersediaan audiens. Kedua simpulan ini sesuai dengan pemikiran Pringle dan Starr. Kajian strategi ANTV untuk memenangkan persaingan dalam industri televisi ini membuka sebuah pemikiran baru, yaitu gambaran strategi yang tidak hanya terpaku pada tayangan on-air, namun juga diperkuat dengan kemasan program off-air.

Kata kunci: Program, Film India, ANTV, Ketersediaan Audiens

\section{PENDAHULUAN}

Dalam melakukan aktivitas, setiap perusahaan menghasilkan sebuah produk, berupa barang ataupun jasa. Termasuk perusahaan media massa seperti stasiun televisi, menghasilkan sebuah produk yang dikenal dengan sebutan 'konten' atau 'program'. Sebagai sebuah produk yang ditawarkan ke pasar, program harus memiliki kemenarikan agar dapat dibeli atau dikonsumsi oleh konsumen (audiens). Untuk itu dituntut usaha bagi pengelola stasiun televisi, agar para audiens tertarik menyaksikan program mereka. Sebaliknya audiens memiliki kebebasan dalam memilih kanal televisi manapun, yang sesuai dengan keinginan, kebutuhan dan harapan mereka dari program tersebut. Seperti dikatakan Morissan (2008:200) program yang baik akan mendapatkan penonton lebih besar, sedangkan program yang buruk tidak akan mendapatkan penonton.

Jumlah penonton ini tercermin melalui perolehan rating dan share dari program yang ditayangkan. Sehingga pengelola televisi harus memiliki kemampuan dalam memprediksi rating dan share program, tinggi atau rendah.

Tassel dan Howfield (2010:157) mengatakan rating yaitu menghitung nilai persentase jumlah rumah tangga atau orang yang menonton suatu program tertentu terhadap seluruh jumlah rumah tangga yang di survei dalam rata-rata menit. Sedangkan share hanya menghitung nilai persentase jumlah orang yang menonton suatu program, terhadap televisi yang menyala saja. Senada dengan Tassel dan Howfield, Baran (2014:190) menambahkan bahwa share memberi gambaran perbandingan pangsa pasar terhadap program televisi saingan. Program televisi dapat diproduksi sendiri atau akuisisi dari rumah produksi
(Production House), dan perusahaan distributor, seperti MD Entertainment, Sinemart, Multivision Plus, Becker Entertainment, Fremantle Media, dan lainnya.

Ada banyak faktor yang harus diperhatikan bagi pengelola televisi sebelum memutuskan untuk memproduksi, akuisisi, dan menjadwalkan sebuah program. Menurut Pringle dan Starr (2006:123-125) yaitu: (1) Strength or Weakness of Competing Stations; mengetahui kekuatan atau kelemahan program televisi saingan, (2) Building Audience Flow; menciptakan dan mempertahankan audiens melalui program, (3) Building Audience Habit; menciptakan kebiasaan audiens dalam menonton, (4) Available Audience; ketersediaan audiens sesuai target yang disasar program, (5) Audience Interest; menarik minat audiens melalui tayangan program, (6) Advertiser Interest; menarik minat pengiklan melalui tayangan program, (7) Budget; kemampuan finansial untuk memproduksi atau akuisisi program, (8) Program Inventory; memiliki persediaan program yang bervariasi dan selalu siap tersedia sesuai dengan kontrak penayangan, (9) Local Production Capabilities, apabila memiliki anggaran, peralatan teknis, dan crew yang handal, mampu untuk memproduksi program lokal yang bervariasi, tidak hanya berita.

Kondisi persaingan televisi saat ini, menurut Morissan (2008:165) harus memiliki strategi yang jelas untuk merebut perhatian audiens. Audiens adalah pasar dan program adalah produk yang ditawarkan.

Pasar audiens menjadi penting dalam kinerja media, seperti yang dikatakan McQuail (2011:250) bahwa kinerja media dalam satu pasar (audiens) dapat 
memengaruhi kinerja pasar lain (pengiklan).

Sementara Fiske (dalam Siregar dkk, 2010:126) mengatakan bahwa media adalah perangkat industri kultural yang terkait erat dengan kapitalisme. Artinya media adalah institusi bisnis yang sangat dipengaruhi pasar. Hidup mati media ditentukan oleh seberapa besar media tersebut bisa diterima pasar, dalam arti seberapa besar khalayak yang bisa diraih oleh media.

Dari penjelasan tersebut dapat dipahami bahwa pentingnya mengenali dan memahami pasar audiens bagi stasiun televisi terhadap program yang ditayangkan, disukai mereka apa tidak.

Dalam artikel ini, penulis akan mengkaji sebuah program yang berhasil merebut perhatian penonton baru-baru ini, yaitu program film India yang ditayangkan ANTV. Program ini merupakan program unggulan ANTV untuk bersaing dengan televisi lain di Indonesia.

Menurut Bambang Lazuardi Manager Qualitative \& Program Development ANTV berdasarkan jawaban pertanyaan melalui email dikatakan bahwa, "film India yang kami tayangkan setiap hari di ANTV merupakan program unggulan kami. Stasiun kami menduduki peringkat pertama dengan share tertinggi di antara stasiun televisi lainnya, dan sumbangan paling besar berasal dari tayangan film India".

Berdasarkan uraian di atas dan sembilan faktor yang dikemukakan Pringle dan Starr, dalam artikel ini penulis membatasi kajian pada ketersediaan audiens (Available Audience) untuk menganalisis tayangan film India ANTV, dikaitkan dengan strategi penjadwalan program pada pola acara.

Untuk itu, penulis merumuskan masalah penelitian, yakni strategi ANTV dalam industri televisi melalui tayangan film India untuk memenangkan persaingan, 1) Bagaimana tayangan film India menjadi program unggulan ANTV? dan 2) Bagaimana strategi ANTV membidik ketersediaan audiens pada tayangan film India untuk memenangkan persaingan?

\section{METODE PENELITIAN}

Penulis menggunakan pendekatan kualitatif yang bersifat deskriptif. Menurut Creswell (2010: 4) penelitian kualitatif merupakan metode-metode untuk mengeksplorasi dan memahami makna yang oleh sejumlah individu atau sekelompok orang dianggap berasal dari masalah sosial atau kemanusiaan.

Proses penelitian kualitatif ini melibatkan upaya-upaya penting, seperti mengajukan pertanyaan-pertanyaan dan prosedur-prosedur, mengumpulkan data yang spesifik dari para partisipan, menganalisis data secara induktif mulai dari tema-tema yang khusus ke tema-tema yang umum, dan menafsirkan makna data.

Laporan akhir untuk penelitian ini memiliki struktur atau kerangka yang fleksibel. Siapapun yang terlibat dalam bentuk penelitian ini harus menerapkan cara pandang penelitian yang bergaya induktif, berfokus terhadap makna individual, dan menerjemahkan kompleksitas suatu permasalahan.

Sementara Kriyantono (2014:69) menjelaskan jenis riset kualitatif deskriptif bertujuan membuat deskripsi secara sistematis, faktual, dan akurat tentang faktafakta dan sifat-sifat populasi atau objek tertentu.

\section{Teknik Pengumpulan Data}

Sedangkan teknik pengumpulan data yang digunakan yaitu observasi, wawancara, dokumentasi, dan gabungan / triangulasi (Sugiyono, 2012:225).

Langkah-langkah pengumpulan data meliputi usaha membatasi penelitian, mengumpulkan informasi melalui observasi dan wawancara, baik yang terstruktur maupun tidak, dokumentasi, materi-materi visual, serta usaha merancang protokol untuk merekam/mencatat informasi. (Creswell, 2010:266). 
Adapun teknik pengumpulan data yang digunakan, yaitu: mewawancarai manager program ANTV dan penonton film India di ANTV, mengamati tayangan film India ANTV (on-air) dan kegiatan lainnya (off-air) yang terkait, serta mengumpulkan dan menganalisis dokumentasi yang tersedia.

\section{HASIL DAN PEMBAHASAN}

Menurut Pringle dan Starr, hal utama ketersediaan audiens adalah target yang disasar sesuai dengan target program, yang ditayangkan di jam tertentu setiap harinya. Secara teori penonton anak-anak dan dewasa sangat potensial. Namun harus dibedakan program untuk harian dan akhir pekan, seperti aktivitas belanja, sosial, olahraga, dan keagamaan.

Penulis akan mengkaji tayangan film India di ANTV berdasarkan uraian penjadwalan program televisi, seperti yang dijelaskan Pringle dan Starr (2006:124), sebagai berikut:

Tabel 1. Pembagian Slot Waktu Siaran dan Ketersediaan Audiens Televisi

\begin{tabular}{|c|c|}
\hline Daypart & Available Audience \\
\hline $\begin{array}{c}\text { Early Morning } \\
(\mathrm{Pkl} .06 .00-09.00)\end{array}$ & $\begin{array}{l}\text { Anak-anak, ibu rumah tangga, pensiunan, pelajar dan pria / wanita dewasa } \\
\text { bersiap berangkat bekerja di luar rumah. }\end{array}$ \\
\hline $\begin{array}{l}\text { Morning } \\
(\text { Pkl. } 9.00-12.00)\end{array}$ & $\begin{array}{l}\text { Sebagian besar anak prasekolah, ibu rumah tangga, pensiunan, dan } \\
\text { pekerja shift (secara giliran). }\end{array}$ \\
\hline $\begin{array}{l}\text { Afternoon } \\
\text { (Pkl. } 12.00-16.00)\end{array}$ & Pekerja yang makan siang di rumah, pelajar yang pulang sekolah. \\
\hline $\begin{array}{l}\text { Early Fringe } \\
(\text { Pkl. } 16.00-18.00)\end{array}$ & Para pekerja telah kembali ke rumah, anak - anak dan juga remaja. \\
\hline $\begin{array}{l}\text { Early Evening } \\
(\text { Pkl. } 18.00-19.00)\end{array}$ & Sebagian besar semua segmen audiens ada di rumah. \\
\hline $\begin{array}{l}\text { Prime Access } \\
\text { (Pkl. } 19.00-20.00)\end{array}$ & Semua segmen audiens tersedia untuk menyaksikan program televisi. \\
\hline $\begin{array}{l}\text { Network Prime Time } \\
\text { (Pkl. } 20.00-23.00)\end{array}$ & $\begin{array}{l}\text { Selama satu jam pertama, sama seperti untuk Prime Access. } \\
\text { Penurunan dimulai sekitar pukul } 21.30 \text {, terutama di kalangan anak-anak, } \\
\text { mereka yang harus bangun pagi-pagi, dan pensiunan. }\end{array}$ \\
\hline $\begin{array}{l}\text { Late Fringe } \\
\text { (Pkl. 23.00-23.35) }\end{array}$ & Sebagian besar orang dewasa. \\
\hline $\begin{array}{l}\text { Late Night } \\
\text { (Pkl. 23.35-02.05) }\end{array}$ & $\begin{array}{l}\text { Sekali lagi, kebanyakan orang dewasa, termasuk pekerja shift } \\
\text { (secara giliran). }\end{array}$ \\
\hline $\begin{array}{l}\text { Overnight } \\
\text { (Pkl. 02.05-06.00) }\end{array}$ & Pekerja shift (secara giliran) dan audiens yang tersedia relatif kecil. \\
\hline
\end{tabular}

Sumber: Pringle dan Starr (2006:124)

\section{Pasar Audiens Televisi}

Sebagai institusi bisnis, media massa (televisi) selalu mencari keuntungan. Melalui program yang dihasilkan, televisi menjual programnya kepada audiens untuk ditonton. Besaran jumlah audiens yang menonton program tersebut, kemudian ditawarkan kepada pemasang iklan. Alasan pengiklan menempatkan iklannya pada ruang-ruang komersil (commercial break) yang tersedia dalam program, tentunya untuk mempromosikan produknya. Picard (1989) menyebutnya dengan 'dual product market', (Albarran, 2010:52). 
Dengan demikian dapat dikatakan bahwa, audiens merupakan hal utama bagi kelangsungan hidup televisi. Audiens menjadi titik sentral, penghubung antara program dan pengiklan. Sebaik apapun sebuah program menurut pengelola televisi, akan sia-sia apabila audiens tidak menyukainya. Begitu pula para pengiklan tertarik untuk menempatkan iklan produknya pada program, karena program tersebut memiliki banyak audiens.

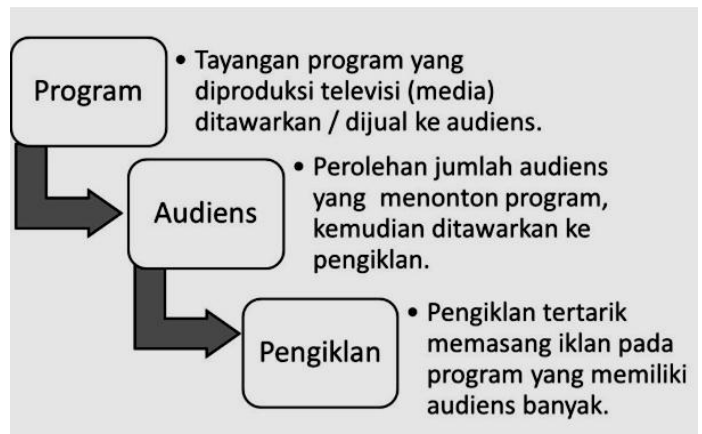

Gambar 1. Dual product market

Sumber: konstruksi penulis berdasarkan Picard (1989) dalam Albarran (2010:52)

Pemahaman tentang audiens oleh pengelola televisi, merupakan hal yang wajib dan menjadi penting agar sebuah program yang dirancang menghasilkan audiens yang tepat. Produser program atau programmer ketika mulai merencanakan sebuah program hendaknya melakukan segmentasi audiens, sebelum membidik target audiens.

Segmentasi pasar audiens adalah suatu konsep yang sangat penting dalam memahami audiens penyiaran dan pemasaran program. Menurut Eric Borkowitz dan rekannya mendefinisikan segmen pasar sebagai "dividing up a market into distinct group that (1) have comman needs and (2) will respond similarly to a market action" (membagi suatu pasar dalam kelompok-kelompok yang jelas yang (1) memiliki kebutuhan yang sama dan (2) memberikan respon yang sama terhadap suatu tindakan pemasaran. Jika ditinjau dari perspektif audiens penyiaran, maka segmentasi pasar adalah suatu kegiatan untuk membagi-bagi atau mengelompokkan audiens ke dalam kotak-kotak yang lebih homogen. (Morissan, 2008:167)

\section{Tayangan Film India di Televisi}

ANTV bukanlah stasiun televisi pertama yang sukses manayangkan film India di Indonesia. Kesuksesan dalam meraih jumlah audiens dan pengiklan yang banyak, pernah diraih sebelumnya oleh stasiun Televisi Pendidikan Indonesia (TPI) pada tahun 1990-an melalui tayangan film India berjudul Mahabharata.

Kesuksesan TPI dengan film kolosal (epik) Mahabharata ini, kemudian berlanjut dengan penayangan film Ramayana, dan drama-drama series India lainnya. Gencarnya TPI menayangkan film India saat itu, membuat singkatan nama TPI 'diganti' oleh sebagian besar masyarakat penonton menjadi 'Televisi Paling India'. Bahkan stasiun televisi ini pernah mendapat protes dari pecinta tayangan film India, karena men-dubbing bahasa India dalam film tersebut dengan bahasa Indonesia.

Kemasan cerita yang dekat dengan kebudayaan Indonesia, tampilan kisah kehidupan sehari-hari, dan dibumbui lagu yang ada dalam film India, merupakan daya pikat bagi masyarakat penonton.

Kemiripan cerita seperti sinetron (sinema elektronik) dan soap opera, yang juga populer di Indonesia, menjadikan tayangan film India dapat meraup 
keuntungan luar biasa. Apalagi hanya TPI saat itu yang menayangkannya tanpa ada saingan dari televisi lain. Keberhasilan TPI kemudian diikuti oleh televisi swasta lain, seperti SCTV menayangkan film India Gala Bollywood dan lainnya.

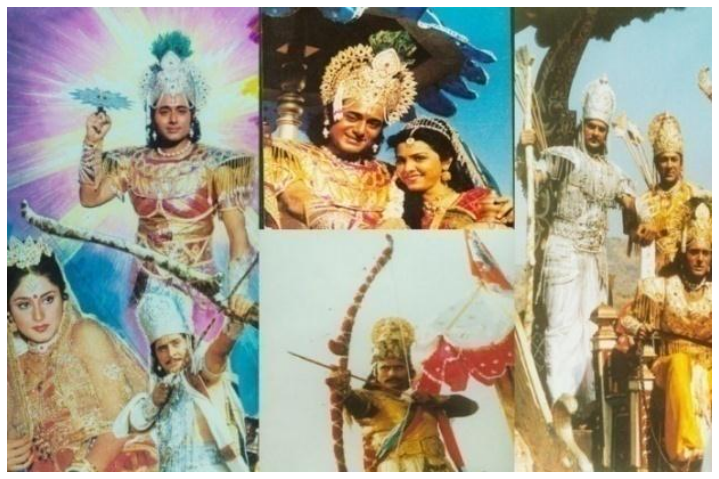

Gambar 2. Serial "Mahabharata" versi India dari tahun 1990-an

Sumber: Dok. istimewa, Tabloidbintang.com

Film India Mendongkrak Share ANTV

Berkaca pada kesuksesan TPI kala itu dan diproduksinya kembali film Mahabharata oleh perusahaan film Swastik Productions Pvt. Ltd tahun 2013, membuat ANTV mencoba untuk menayangkan serial ini, seperti dikatakan Otis, Direktur Operasional ANTV yang dikutip swa.co.id, bahwa ANTV memutuskan untuk fokus menayangkan series dari luar, dan salah satunya adalah India. Selain memiliki potensi market yang besar, series India juga memiliki kedekatan budaya dengan Indonesia. Keputusan ANTV ini mendapat sambutan luar biasa dari penonton.

Serial Mahabharata menjadi titik awal kesuksesan ANTV meraih audiens, yang juga turut mempopulerkan nama Shaheer Sheikh di tanah air. Diikuti dengan penayangan serial India lainnya di jam keluarga, seperti Mahadewa, The Adventure of Hatim, dan Jodha Akbar. ANTV menjadi televisi peringkat satu, dan sukses menjadi trendsetter penayangan serial India. Posisi ANTV semakin kuat saat menghadirkan serial Uttaran dan berbagai judul lainnya seperti Thapki, Anandhi, Gopi, dan lainnya. (kompasiana.com)
Pada marketing.co.id ditulis, sejak menayangkan serial India pada September 2013, posisi ANTV dalam hal kepemirsaan dan pendapatan iklan meningkat signifikan. Memasuki tahun 2015, posisi ANTV di kepemirsaan maupun pendapatan iklan selalu bercokol di posisi kedua. Bahkan, posisi pertama yang selama ini ditempati RCTI, pernah tergeser ANTV di akhir tahun 2016 dan awal tahun 2017. Pendapatan iklan ANTV pun cemerlang, mencapai Rp. 200 miliar per bulannya (Mix.co.id).

Merujuk data Nielsen 2016, share kepemirsaan ANTV mampu menyalip SCTV dan Indosiar, yakni tembus $15,2 \%$ di November 2016. Dengan perolehan itu, ANTV menempati posisi kedua dan hanya beda tipis dengan audience share RCTI, yakni 0,8. Bahkan, di penghujung tahun 2016, tepatnya 29 dan 30 Desember, total kepemirsaan ANTV mampu menyalip RCTI, dengan menempati share kepemirsaan tertinggi. Otis menyatakan, "awal tahun lalu, 1 Januari 2017, total kepemirsaan ANTV juga mampu menempati posisi pertama," (swa.co.id). 


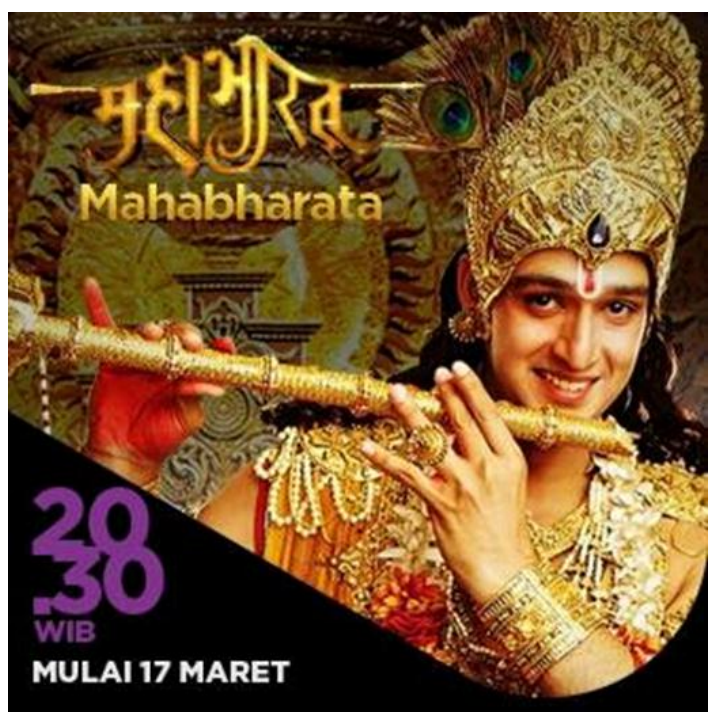

Gambar 3. Serial "Mahabharata" versi baru tayang di ANTV Sumber: Dokumentasi ANTV

\section{Meet and Greet ANTV India Series}

Kerja keras yang dilakukan ANTV untuk menjadi televisi 'nomor wahid dari nomor buncit' di antara televisi saingan, bukanlah hal mudah. Prestasi yang telah ditorehkan ANTV dalam sejarah pertelevisian Indonesia dapat bertahan lebih dari setahun hingga awal 2018 ini.

Untuk mempertahankan posisi nomor satu tersebut, ANTV terus berpacu untuk merebut hati pemirsanya. Tidak hanya melalui tayangan film India yang dapat disaksikan melalui televisi (program on-air), namun mengemas berbagai kegiatan lainnya (program off-air).

Salah satu program off-air yang dimaksud adalah mendatangkan artis pemeran film India ke Indonesia. Mendatangkan tokoh-tokoh dalam tayangan film yang menjadi favorit pemirsa ini, tentunya disambut dengan penuh suka cita oleh para penggemarnya. Bagaimana tidak, tokoh yang sedianya hanya dapat disaksikan pemirsa melalui tayangan film semata, kini sosoknya dihadirkan di depan mata dan berinteraksi langsung dengan masyarakat Indonesia.
ANTV mengemas program off-air tersebut dalam sebuah acara yang diberi nama 'Meet and Greet ANTV India Series'. Acara ini diselenggarakan di beberapa kota, seperti Jakarta, Lampung, Jogyakarta, Kebumen, Majalengka, Medan, Cirebon, Pandeglang, Bali, dan kota-kota lainnya.(www.antvklik.com).

Meet and Greet ANTV India Series, makin memperlihatkan bahwa program film India memiliki tempat istimewa di hati pemirsanya. Ribuan penggemar yang memadati acara ini dimanjakan dengan interaksi 'tokoh idola' mereka. Penampilan melalui lagu, tari dan sapaan langsung dari artis film India ini, makin menciptakan suasana yang akrab bahkan histeria para penontonnya.

Roadshow ke berbagai kota di Indonesia, tercatat selalu menyedot perhatian masyarakat setempat. Bahkan saat menggelar Meet and Greet ANTV India Series di Lubukpakam, acara ini dihadiri oleh 20.000 penonton. Seperti dikutip www.medanbisnisdaily.com, Andrian, Manager Off Air ANTV, mengatakan, "ini penonton yang terbanyak di Indonesia. Pokoknya luar biasa banget,". 


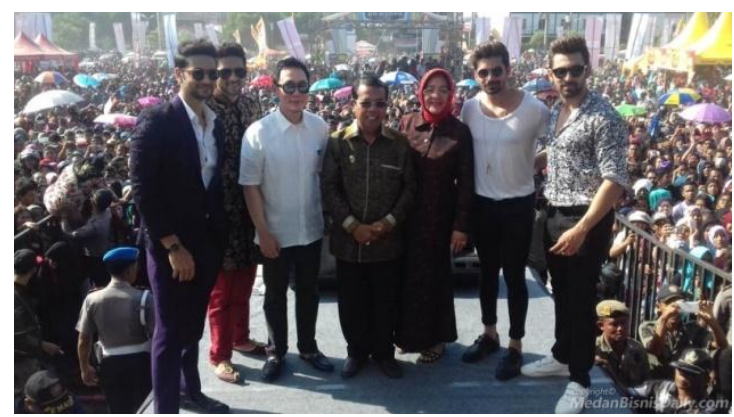

Gambar 4. Meet and Greet ANTV India Series di Lubukpakam

Sumber: Dokumentasi www.medanbisnisdaily.com

Langkah-langkah yang dilakukan ANTV melalui tayangan film India di televisi (on-air) dan menguatkannya melalui kegiatan off-air, menurut penulis merupakan bentuk komitmen untuk menjadikan film India sebagai program unggulan di televisinya.

Menurut pengamatan penulis, kegiatan Meet and Greet yang dilakukan ANTV ini sebagai bentuk pembeda dan keunggulan berkompetisi dengan stasiun televisi lain di Indonesia.

\section{Ketersediaan Audiens film India ANTV}

Ketika pertama kali mengudara tahun 1993, ANTV memosisikan sebagai stasiun televisi sport, dengan menghadirkan tayangan olahraga. Tahun-tahun berikutnya ANTV telah mengalami empat kali rejuvinasi (peremajaan) dalam memosisikan diri sebagai perusahaan media. Tahun 1995. Memosisikan sebagai televisi musik (MTV TV), kemudian perempuan TV, dan tahun 2006 merubah konsepnya menjadi general entertainment, dengan menayangkan banyak sinetron, seperti televisi saingan RCTI dan SCTV. (swa.co.id)

Perubahan posisi berulangkali yang dilakukan ANTV belum membuahkan hasil. Kemudian ANTV mencoba melakukan reposisi pasar dari yang semula membidik kalangan remaja sebagai target utama menjadi wanita 15 tahun ke atas dan anak-anak.

Menurut Otis, "ANTV membidik target utama perempuan 15 tahun ke atas. Adapun secondary target ANTV adalah anak-anak usia 5-10 tahun serta pria usia 15 tahun ke atas. Dari kelas sosial, maka yang dibidik ANTV adalah upper class, upper middle 1 class, dan upper middle 2 class".

Kemudian langkah berikutnya yang dilakukan ANTV adalah upaya memenuhi selera audiens melalui tayangan film India. Seperti dijelaskan sebelumnya bahwa tayangan film India Mahabharata merupakan kali pertama yang dilakukan ANTV, dan mendapat sambutan baik dari audiens. Kemudian diikuti series India lainnya.

Penulis juga menghimpun beberapa Vox Populi dari beberapa penonton ANTV. Berdasarkan data yang berhasil didokumentasikan melalui pertanyaan: program apa yang menjadi favorit pemirsa di ANTV? Penulis memperoleh jawaban yang hampir serupa. Mayoritas jawaban yang diberikan, yakni tayangan film India. Data ini mendeskripsikan bahwa tayangan film India menjadi program ANTV yang menempati posisi teratas bagi audiens di Indonesia.

Terkait program acara televisi, ANTV menayangkan film India sejak pagi hingga malam hari. Tayangan ini menyasar target audiens anak-anak dan dewasa. Baalveer dan Veera adalah tayangan film India yang diperuntukkan untuk audiens anak-anak. Masing-masing ditayangkan pada pukul 07.45 WIB dan 12.00 WIB.

Selanjutnya, tayangan film India dengan target dewasa tampaknya mendominasi program acara di ANTV. Pada jadwal acara di ANTV, penulis mendata tayangan film India memiliki rentang waktu yang cukup panjang, yaitu 
pukul 11. $30-21.00$ WIB. Diantaranya, series India berjudul Anandhi, Thapki, Gopi, Lonceng Cinta, Ashoka dan Mohabbatein.

(https://acara.co.id/event/jadwal-antv-2-9oktober-2016/).
Pada tahun 2018, ada dua slot waktu tayang untuk film India terbaru di ANTV menurut Bambang Lazuardi, yaitu Pardes, pukul 16.45 - 18.30 WIB, dan Chandranandini, pukul 18.30 - 20.00 WIB, mulai tayang 3 Januari 2018.

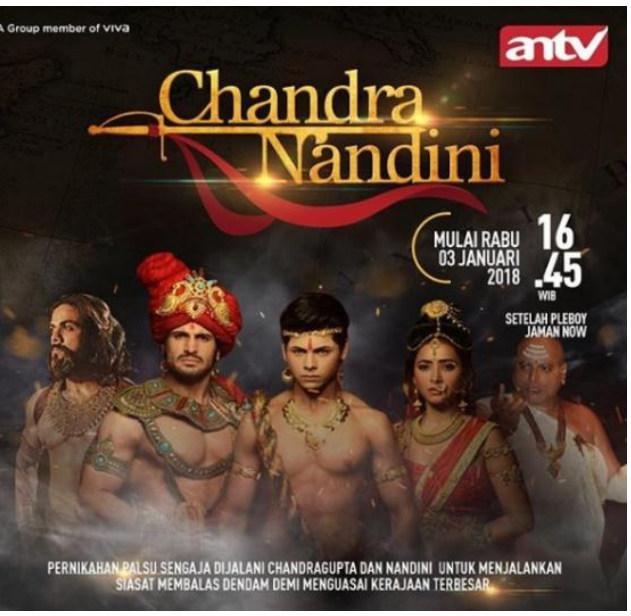

Gambar 5. Serial terbaru ANTV "Chandranandini"

Sumber: duniatv.net

Berdasarkan data yang diperoleh dari rating program tv (facebook.com), serial Chandranandini memperoleh rating
4.6 dengan share 18.0 berada di urutan kedua setelah tayangan sinetron Anak Langit SCTV.

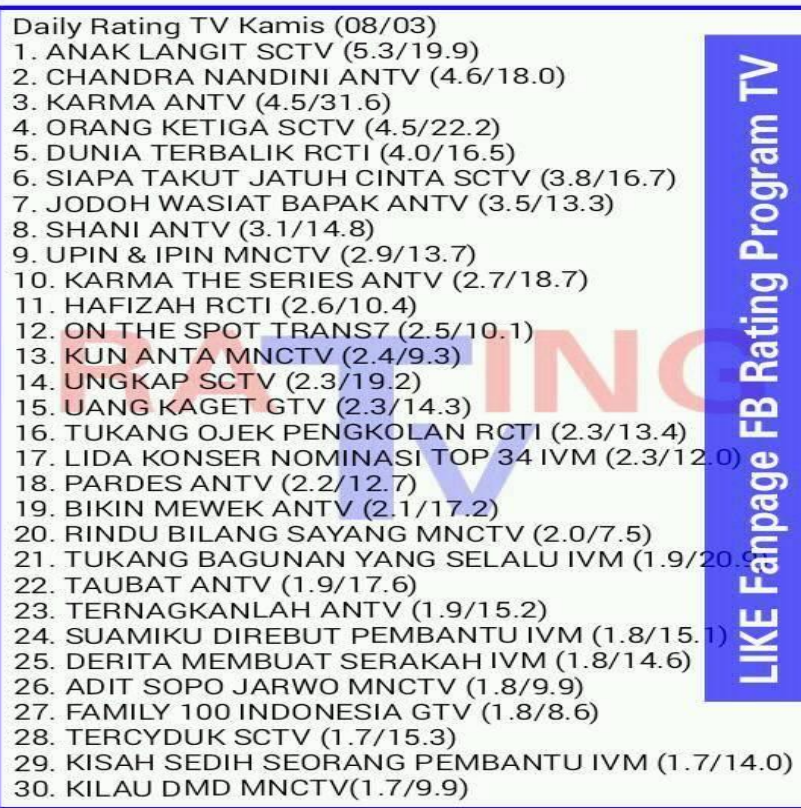

Gambar 6. Rating dan Share TV

Sumber: facebook-ratingprogramtv 
Data rating dan share serial terbaru ANTV Chandranandini tentu sangatlah baik. Sebagai sebuah program baru dengan jam tayang menggantikan program pesbukers, yang memiliki ketersediaan audiens wanita, menjadi modal untuk mendapatkan rating dan share yang lebih baik lagi.

Tayangan film India masih terus dipertahankan oleh ANTV mengingat program on-air ini berhasil merangkul jumlah pemirsa yang tinggi. Seperti dikutip dalam artikel www.tribunnews.com, menurut Anindya N Bakrie, Komisaris Utama PT. Intermedia Capital, Tbk (MDIA) yang memayungi ANTV, menyatakan bahwa keberhasilan ANTV disesuaikan dengan minat penonton yang mengacu pada hasil analisa data dan informasi yang kuat.

Lebih lanjut dikatakan, data-data itu dibagi menjadi beberapa bagian waktu yang disebut daypart. Di setiap daypart terdapat program unggulan yang disesuaikan dengan target pemirsa. Anindya menambahkan, "setiap daypart adalah prime time bagi pemirsa yang kami bidik, hal inilah yang membuat ANTV berhasil mencetak rekor TV share".

Terkait target pemirsa, perubahan yang telah dilakukan ANTV dari pemirsa remaja ke wanita 15 tahun ke atas (dewasa) sebagai target utama, dan anak-anak serta pria sebagai target kedua, merupakan suatu strategi yang tepat, seperti dikatakan Pringle dan Starr, terkait hal utama ketersediaan audiens potensial, adalah dewasa dan anak-anak.

Ada beberapa alasan wanita menyukai tayangan film India, berdasarkan data yang diperoleh penulis dari Vox Populi. Antara lain konflik yang ditampilkan seru, kostum yang digunakan para pemerannya bagus-bagus, banyak pesan moral, terpukau dengan ketampanan dan kecantikan artis/pemain, ada sejarah, penasaran terhadap ceritanya, kualitas gambar dan suara (dubbing) bagus, lagulagunya enak dinikmati.
Sementara itu, jadwal tayangan film India yang cukup panjang dalam kurun waktu satu hari, menurut penulis sebenarnya memiliki resiko yang besar, apabila satu atau dua judul yang ditayangkan tidak dapat memikat perhatian audiens. Sehingga akan mengganggu pada penurunan share yang diperoleh. Akan tetapi, keberanian ANTV ini terbukti berhasil mendulang rating dan share yang baik, karena yang menjadi target utama film India tersebut adalah wanita dewasa.

\section{SIMPULAN}

Berdasarkan hasil dan pembahasan yang telah dikaji dalam uraian sebelumnya, penulis menyimpulkan bahwa:

1) Tayangan film India di ANTV berhasil menjadi program unggulan hingga saat ini. Film India merupakan program acara yang sesuai dengan target audiens anak-anak dan dewasa (khususnya wanita). Kejelian ANTV dalam menayangkan film India sangat didasarkan pada target audiens yang diusung yakni pemirsa wanita (target utama) dan pemirsa anak-anak serta pria dewasa (target kedua). Ketepatan ANTV dengan menyajikan program televisi on-air berupa film India, berhasil menyedot perhatian penonton sehingga menjadi program yang unggul hingga saat ini.

2) Uraian penjadwalan program acara di ANTV menggambarkan kesesuaian pembagian slot waktu siaran dan ketersediaan audiens televisi yang dipolakan oleh Pringle dan Starr. Demikian pula dengan pernyataan teoritisnya mengenai audiens potensial yakni penonton anak-anak dan dewasa. Secara garis besar, jadwal tayangan film India di ANTV terpola dalam 7 (tujuh) daypart. Kategori daypart early 
morning dan afternoon untuk tayangan film India dengan target penonton anak-anak. Sementara untuk target penonton dewasa masuk dalam kategori daypart early morning, morning, afternoon, early fringe, early evening, prime access, dan network prime. Masing-masing daypart diketahui memiliki ketersediaan audiens yang dibidik secara akurat oleh ANTV. Penonton potensial dalam setiap daypart disuguhi tayangan acara yang sesuai sasaran.

Kajian strategi yang dilakukan ANTV untuk memenangkan persaingan dalam industri televisi ini, menurut penulis membuka sebuah pemikiran baru. Gambaran strategi yang tidak hanya terpaku pada tayangan film India secara on-air semata. Namun, kemasan program off-air seperti 'Meet and Greet ANTV India Series' turut menguatkan tayangan film India di ANTV.

\section{DAFTAR PUSTAKA}

Albarran, Alan B. (2010). The Media Economy. First Published by Routledge. New York.

Arifin, Choirul. (2016). Diakses, 4 Januari 2018, dari http://www.tribunnews.com/bisnis/ 2016/04/29/banting-stir-kepenonton-wanita-dan-anak-anak-tvshare-antv-melonjak-148-persen

Baran, J. Stanley. (2014). Introduction to Mass Communication, Media Literacy, and Culture. Eighth Edition. McGraw-Hill.

Bakrie, Anindya N. (2016). http://www.tribunnews.com/bisnis/ 2016/04/29/banting-stir-kepenonton-wanita-dan-anak-anak-tvshare-antv-melonjak-148-persen
Burhanudin, Toni. (2017). Diakses, 17 Januari 2018, dari https://marketing.co.id/bollywoodsebagai-pendongkrak-rating/

Creswell, W. John. (2010). Research Design, Pendekatan Kualitatif, Kuantitatif, dan Mixed, Penerjemah: Achmad Fawaid. Cetakan 1. Yogyakarta: Pustaka Pelajar.

https://acara.co.id/event/jadwal-antv-2-9oktober-2016/). Diakses, 20 Februari 2018.

https://www.antvklik.com/schedule. Diakses, Januari-Maret 2018

http://www.duniatv.net/2018/01/chandranandini-tayang-di-jampesbukers.html. Diakses, 10 Maret 2018.

https://www.kompasiana.com/rizqiarie48/ot is-hahijary-maestro-barupertelevisianindonesia_595295a464afbd1a568b 7a32. Diakses, 5 Maret 2018.

http://www.medanbisnisdaily.com/news/onl ine/read/2017/08/27/3767/20_000_ penonton_hadiri_meet_greet_antv_ india_series_di_lubukpakam/. Diakses, 10 Maret 2018.

https://swa.co.id/businesschampions/brands/perjalanan-antvrebut-hati-pemirsa. Diakses 8 Januari 2018.Kriyantono, Rachmat. (2014). Teknik Praktis Riset Komunikasi. Cetakan 7. Jakarta: Kencana Prenada Media Group.

https://www.tabloidbintang.com/extra/nosta lgia/read/5556/mengenangmahabharata-versi-1990an-yangpernah-tayang-di-tpi.

McQuail, Denis. (2011). Teori Komunikasi Massa. Penerjemah: Putri Iva Izzati. Edisi 6. Jakarta: Salemba Humanika.

Morissan. (2008). Manajemen Media Penyiaran: Strategi Mengelola Radio \& Televisi. Edisi Pertama, Cetakan ke-1. Jakarta: Kencana Prenada Media Group. 
Prahadi, Yeffrie Yundiarto. (2017). Diakses, 10 Januari 2018, dari https://swa.co.id/swa/trends/manag ement/cerita-menarik-dari-reposisiantv.

Pringle, Peter K, Starr, Michael F. (2006). Electronic Media Management. Fifth Edition. Burlington, USA: Elsevier.

Siregar, Amir Effendi Dkk. (2010). Potret Manajemen Media di Indonesia, Penyunting: Diyah Hayu Rahmitasari, Cetakan 1. Yogyakarta: Total Media kerjasama dengan Program Studi Ilmu Komunikasi Universitas Islam Indonesia.
Sugiyono. (2012). Metode Penelitian Kuantitatif, Kualitatif, dan $R \& D$. Cetakan 17. Jakarta: Alfabeta, CV.

Tassel, Joan Van, Howfield, Lisa Poe. (2010). Managing Electronic Media, Making, Marketing, \& Moving Digital Content. Elsevier Inc.

Rating Program TV. (2018). Diakses 10 Maret 2018, dari https://www.facebook.com/174811 2535509268/photos/a.19309883438 88352.1073741829 .174811253550 $9268 / 1975984666055386 /$ ?type $=3$ \&theater 